\title{
Structural, Morphological and thermal properties of Nano filler Produced from Date Palm-based Micro Fibers (Phoenix Dactylifera L.)
}

\section{Othman Y Alothman}

King Saud University

H.M. Shaikh

King Saud University

Basheer A. Alshammari

King Abdulaziz City for Science And Technology

Mohammad Jawaid ( $\square$ jawaid_md@yahoo.co.in )

Universiti Putra Malaysia https://orcid.org/0000-0001-5348-5740

\section{Research Article}

Keywords: Nanofillers, Date palm, Morphology, Crystallinity, Thermal stability

Posted Date: June 2nd, 2021

DOI: https://doi.org/10.21203/rs.3.rs-533558/v1

License: (9) This work is licensed under a Creative Commons Attribution 4.0 International License.

Read Full License

Version of Record: A version of this preprint was published at Journal of Polymers and the Environment on July 5th, 2021. See the published version at https://doi.org/10.1007/s10924-021-02224-0. 


\section{Abstract}

In this century, the development of nano-sized filler from biomass material has become the main focus of industries in achieving their final green composite product for wide range of applications. From commercial and environmental point of view, fragmentation and downsizing of waste lignocellulosic fibers without chemical treatments into small size particles is a viable option. In this study, an attempt was made to produce nano-sized lignocellulosic fillers from date palm micro fibers via simple mechanical ball milling process. The resultant nanofillers as well as the microfibers were characterized in details by various analytical techniques, including transmission electron microscopy (TEM), scanning electron microscopy (SEM), particle size analysis (PSA), Energy Dispersive X-Ray (EDX), X-ray diffraction (XRD), thermogravimetric analysis (TGA), and differential scanning calorimetry (DSC) to assess their structureproperty relationship. From microscopy examination, the nanofillers showed a heterogeneous mix of irregular shaped particles, and while having a size ranging of 30-110 nm in width and 1-10 mm length dimensions. Also, the crystallography analysis revealed the crystallinity had mildly declined from microfibers $(71.8 \%)$ to nanofiller $(68.9 \%)$ due to amorphization effect. As for thermal analysis, the nanofillers exhibited relatively stable in both heat resistance and thermos changing behavior, suggesting its suitability for composite fabrication process at high temperature. Thus, the produced nanofillers can be used as a low cost reinforcing agent in the future for versatile polymer-based composite systems.

\section{Introduction}

Due to the growing awareness regarding environmental concerns and the reduction of finite petroleum products, alternatives to synthetic materials are being actively sought. Larger carbon footprints, pollution, energy intensive fabrication processes, recycling and waste management are some of the issues associated with synthetic fibers and subsequent composites. Therefore, natural materials are considered as one of the most crucial components in various applications. Considerable activities have been devoted towards research and development of such materials [1]. In order to minimize environmental impacts, research studies are focusing on eco-friendly natural lignocellulosic fibers owing to characteristics such as biodegradability, low density, low cost, non-toxic nature, adequate mechanical properties and abundant availability [2]. Besides, new policies are strongly focusing on the renewables alternatives materials to reduce the environmental issues associated with synthetic materials. These policies are supporting the effective use of bio-composites produced from various natural fibers. The future prospects for bio-composites are based on the balance between performance, economics and sustainability [3].

Typically, natural fibers include cotton [4], jute [5], coir [6], hemp [7], flax [8], kenaf [9], bamboo [10], sugarcane [11], silk [12], wool [13], date palm [14], pineapple [15], sisal [16], baggase [17], ramie [18], alfa [19] composed of cellulose, hemicellulose, lignin, pectin and waxes. Hemicellulose surrounds the cellulose in the fiber; while lignin is known to act as binders for cellulosic fibers. Factors influencing performance and properties of such fibers are extraction parameters, growth conditions, climate, environment, soil composition, fertilizers, plant location, extraction techniques and chemicals used during extraction. Structural factors such as chemical composition, defects, microfibril angle and structural 
dimensions are also influencing factors in the determination of fiber final properties [20]. Extensive research activities are being diverted to develop bio-composites with the use of these natural fibers to meet the industrials needs with mechanical properties and performance comparable to synthetic composites during life-cycle assessments [21].

Despite all these advantages and progress in bio-composites, there are many limitations associated with them. These limitations include poor fiber/matrix adhesion, hydrophilicity, agglomeration of fibers and lack of fabrication processes. These shortcomings lead to the loss in required mechanical properties and hindrances in commercialization of these composites. Different physical and chemical techniques are employed to overcome these issues. These technique treatments modify the surface of fibers to have better adhesion and compatibility between fiber and matrix and reduce the agglomeration effect [22]. Biocomposites have a vast range of applications which include construction, textile, packaging and automobile industries. Automobile industries have been successfully using bio-composites to make dashboard parts, cupholders, door panels and exterior parts. In the construction industry, bio-composites are used to manufacture doors, window panels, matting and ceilings $[23,24]$.

Date palm trees (Phoenix Dactylifera L.) are rich in lignocellulosic fibers. Date palm trees are normally grown in tropical and sub-tropical regions. The Arab countries are rich in date palm trees and are the larger sources for natural fibers. Their growth is dependent on environmental conditions as well as the quality of the soil. Natural fibers can be obtained from several different parts of the tree include stems, mesh, leaflets and the midribs. The midribs are center part that connects leaves while the mesh is bark or the surface of the tree. The obtained fibers are incorporated in various synthetic matrix materials such as polyester, epoxy, polyethylenes and polypropylene. However; biodegradable polymer matrix materials such as Poly-lactic acid(PLA), Poly butylene succinate(PBS), Poly ( $\varepsilon$-caprolactone) (PCL) and Poly hydroxyalkanotes (PHA) are also used $[25,26,27]$. There are several parameters to control the compatibility of fibres with matrix materials include type, loadings, surface area and aspect ratio. These factors also determine the possible applications for final applications. Reinforcement of date palm tree fibers in various polymer matrix materials increases acoustical, thermal and mechanical properties of biocomposite. These properties are additional improved through surface treatments of fibers. However, properties of bio-composites are further enhanced by inclusion of nano-sized fibers. Nano-sized fibers, also known as nanofillers are commonly obtained from microfibers by treating them with strong acids to disintegrate the fibers structure into nano-scale dimension. With the hydrolysis treatment, amorphous regions of fibers are expelled and only crystalline regions remain, which impart a high degree of crystallinity to the nanofillers which in return increase mechanical properties of the resultant composite. Other techniques include mechanical and alkaline extraction methods have also been used to produce nanofillers from microfibers [28-30].

According literature study, various research works have been conducted on the use of date palm tree fibers as reinforcement for bio-composites. Similarly, different approaches were also reportedly employed for producing small size cellulosic fiber fillers. One of the recent study by Alothman et al. [31], had successfully prepared cellulose nanocrystals from date palm tree fibers using combined acetic/sulphuric 
acid hydrolysis treatments. From their results, good aspect ratio of cellulosic nanocrystals was obtained, suggesting the cellulose nanocrystals as well as other different micro- or nano- particles could be produced from date palm fibers, which considerably have great potential used for various applications. Moreover, some recent publications have interested on fabricating low cost on both nano- and microfibres/fillers for enhancing the strength properties of bio-materials [32,33]. As far as we know, there is no study dealt with characterization for micro/nano-fillers. Therefore, in present work, the novelty focuses on the using of ball milling to prepare of nano-fillers from date palm micro-fibers. Both obtained nano- and micro-fibres/fillers were well characterized to comprehensively evaluate their potentials to be used as reinforcing agent for our future work in bio-composites application.

\section{Materials And Methods}

\section{Preparation of Nanofillers}

In this study, the waste date palm residue was collected from the farms outskirt of Riyadh, Saudi Arabia. This residue, firstly cleaned by tap water in order to remove attached impurities, and dust particles. It was then kept in large container filled with fresh water for another one week for retting at room temperature. Finally, it was dried at $90-100^{\circ} \mathrm{C}$ in ordinary oven for 3 days for removal of moisture [34]. It was then crushed with industrial grade crushing machine to obtain fine powder (microfibers). This powder was sieved by using $38 \mu \mathrm{m}$ ASTM type sieve and then collected for ball milling. The microfibers was reduced to nanoscale size (nanofillers) by dry milling with a planetary ball mill (Pulverisette 7 Premium, Fritsch Co. Germany). The milling was achieved in $15 \mathrm{ml}$ zirconia container with a $10 \mathrm{~mm}$ zirconia balls, and material to ball ratio kept 1:10. A total ninety-nine cycle of 15-minute were maintained with 15 minutes of pause time between each cycle. The RPM was kept constant i.e. 300 throughout the process. The digital images for microfibers and nanofillers are shown in Figure 1. The obtained microfibers and nanofillers were also used for further characterization.

\section{Analysis of nanofillers size}

The size of the nanofillers was determined by Zetasizer Nano-ZS (Malvern Instruments, UK) at the scattering angle of $90^{\circ}$ and $25^{\circ} \mathrm{C}$ temperature after appropriate dilution (1:200) of the samples with Milli$\mathrm{Q}$ water, sonicated and filtered through 0.45 micron membrane filter.

\section{Morphological analysis}

Transmission electron microscopy (TEM) imaging was performed to study the nanofillers structure by using a JEM-1400 (JEOL, Japan) field-emission electron microscope operating at an accelerating voltage of $120 \mathrm{kV}$. In sample preparation, the nanofillers was mixed with ethanol and deposited on copper grid substrate for drying before viewing. In addition, another morphological characterization, including the elemental analysis was also carried out through a scanning electron microscopy (SEM) coupled with Energy Dispersive X-ray (EDX) facility (JEOL, JSM-6360A, Japan). A small amount of dried powder was 
dispersed in ethanol, sonicated for about 30 minutes and drop applied on the conductive carbon tape attached to the sampling stub. All the samples were gold sputtered prior to observation.

\section{Wide angle X-ray diffraction (XRD) analysis}

Wide angle X-ray diffraction (XRD) analysis was carried out to investigate the crystalline behavior of the samples. A computer-controlled wide-angle goniometer coupled to a sealed-tube source of $\mathrm{Cu}-\mathrm{Ka}$ radiation $(\lambda=1.54056 \AA)$ was used. All samples were scanned at $5^{\circ} / \mathrm{min}$ and $2 \theta$ range from $5^{\circ}$ to $60^{\circ}$.

\section{Thermal Analysis}

Thermogravimetric analysis (TGA) was performed using Shimadzu thermal analyzer (Model: DTG-60H). The alumina pan was filled with 10-15 mg of the sample. Subsequently, the samples were heated from room temperature to $900^{\circ} \mathrm{C}$ at heating rate of $20^{\circ} \mathrm{C}$ /minutes. The analysis was done under a nitrogen atmosphere with a flow rate of $\left(50 \mathrm{~cm}^{3} / \mathrm{min}\right)$ and accordingly, the corresponding weight loss was recorded.

In order to study the thermo-molecular behavior of samples, a differential scanning calorimetry (DSC) (Shimadzu DSC-60, Japan) was used. The samples were heated from room temperature to $300^{\circ} \mathrm{C}$ at a rate of $10^{\circ} \mathrm{C} /$ minutes under nitrogen purge condition.

\section{Results And Discussion}

\section{Effect of ball milling}

Ball milling is low cost and environmental friendly, and is used worldwide in industrial scale. Planetary ball milling is a powerful and reliable method for reducing the size of fillers to the nanoscale. This mechanism is largely based on centrifugal accelerating force rather than gravitational accelerating force, resulting in a short time requirement for the process [34]. Moreover, several others parameters such as time of each cycle, total number of cycles, pause time between each cycles, milling balls size speed (RPM), material to ball weight ratio, nature of the fillers etc. can affect the final properties of the fillers. Therefore, understanding overall procedure of ball milling is complex and challenging in order to get desired shape and size of the fillers. This conditions ( 15 minutes' cycles -15 minutes' pause time between each cycle-total 99 cycles and 300 RPM) have been chosen after extensive trials of the experiment (data not shown).

\section{Morphological studies}

The morphology of nanofillers is illustrated in Figure 2 by TEM examination. Those nanoparticles revealed in a heterogeneous mix of quadrilateral and irregular shapes. This evidenced the ball milling treatment had effectively disintegrated the micro-fibers into varying nano-sized feature. Apparently, the pack-like structure of quadrilateral-shaped particle may impart them with highly preserved rigidity for advantageous application in reinforcing composite materials. In size measurement from TEM image, 
they presented a ranging size of about $30-110 \mathrm{~nm}$ in both width and length dimensions. It was similar to the findings from Saba et al. [34], who had obtained a nanofiller size up to $100 \mathrm{~nm}$ from oil palm empty fruit bunch fibers in a previous study, by treating the ground fiber material with bromine water and tin chloride solution, followed by cryocrushing and ball milling processes. As from Zetasizer analysis (Figure S2), those particles exhibited relatively consistent size at around $300 \mathrm{~nm}$. Despite this size is far larger than the size shown in TEM image, the results is still considerably valid for Zetasizer analysis since this equipment is more accurately used in measuring round shape particles rather than nanofillers particles with diverse shapes. Another explanation was likely due to the poor dispersion of nanofillers in the aqueous solution and ultimately resulted in the agglomeration into larger particles. This was in agreement with the Nanoplus analysis results (Figure S3), where the particles showed three distinct sizes at $81.3 \mathrm{~nm}, 159.0 \mathrm{~nm}$, and $850.2 \mathrm{~nm}$, respectively, indicating the fillers have a diameter of $81.3-159.0 \mathrm{~nm}$, while with a length at around $850.2 \mathrm{~nm}$ approaching micron meter.

As viewed by SEM microscopy (Figure 3), the microfibers are presented as scattering particles, as a result of the deposition on carbon tape through ethanol solvent evaporation process. From surface morphology, the particles revealed a smooth texture, which promoted by the extensive impact and shear forces generated from mechanical ball milling. Meanwhile, the microfibers also showed random shape feature that could aid in promoting its fire retarding behavior as filler in composite materials due to non-uniform transmission/conduction of heat at each point in time [34,35]. Moreover, a few microns in diameter and while tens of micrometer in length was displayed by the microfibers, suggesting the fiber is suitable acting as a micro-filler in composite matrix fabrication. For elemental analysis (Figure 4), microfibers revealed carbon and oxygen as their major compositional elements, implying the fiber is mainly composed of hydrocarbon compounds. In addition, the traces for magnesium, silica, chloride, calcium and iron, indicating the typical residual elements for a plant biomass fiber [36].

\section{Thermal analysis}

The thermo-stability of the samples is evaluated by TGA and DSC curves as depicted in Figure 5 and Figure 6, respectively. From TGA curve (Figure 5), four distinct phases were revealed by both samples, i.e. moisture evaporation, hemicellulose decarboxylation, cellulose decomposition, and lignin pyrolysis. At beginning, both samples showed weight loss in $70-130^{\circ} \mathrm{C}$ temperature regions, in corresponding to the evaporated moisture content. However, the microfibers lost more weight at this region when comparing to nanofillers. It was probably caused by the greater free volume in microfibers that had higher affinity in entrapping water molecules. In subsequent weight loss stage at $250-350^{\circ} \mathrm{C}$, it involved the decomposition process for hemicellulose and cellulose. This was attributing to their closely similar structural feature built-up with adjacent intermolecular linkage via physically twisting and hydrogen bonding [37]. Additionally, the microfibers exhibited slightly higher decomposition temperature at $263.2^{\circ} \mathrm{C}$, when compared to nanofillers at $260.8^{\circ} \mathrm{C}$ temperature. It was possibly contributed by the lower crystallinity as well as the smaller nanoscale size of nanofillers that induced it for earlier thermal degradation. Between $350-500^{\circ} \mathrm{C}$, the liquefaction and gasification process happened for lignin since this compound had strong fire retardant behavior. At final phase, microfibers sample showed constant weight beyond $550^{\circ} \mathrm{C}$, 
whereas nanofillers continued to lose weight and only presented constant weight after $620^{\circ} \mathrm{C}$. This evidenced the thermal degradation is relatively consistent in nanofillers, which may endow it with tunable properties for high temperature fabrication process.

As for DSC analysis (Figure 6), both samples showed broad endotherms extending from $70^{\circ} \mathrm{C}$ to $140^{\circ} \mathrm{C}$ temperature, which basically correlated to the water vaporization process [38]. The enthalpy heat gained by microfibers at this temperature range was $65.09 \mathrm{~J} / \mathrm{g}$, which remarkably larger than the nanofillers sample with $14.82 \mathrm{~J} / \mathrm{g}$. This showcased the microfibers required higher heat energy for evaporating larger water content that in line with the weight loss shown in TGA curve. Besides this, the nanofillers revealed second wide endotherm at around $230^{\circ} \mathrm{C}$ with $25.33 \mathrm{~J} / \mathrm{g}$ enthalpy heat, in correlating to the energy required to decompose cellulose-based compounds. But for microfibers, it was presented as horizontal curve rather than in endothermic band. This was possibly due to the ball milling effect that had gradually decreased the fiber compactness of nanofillers after numerous cycles of treatment and subsequently reduced its thermal resistance in withstanding high temperature. Beyond this point, both curves rising up to likely form an exothermic band for heat release in order to break down the bonds of cellulose and hemicellulose components. Thus, the analyzed DSC results herein agreed well with the TGA curves.

\section{X-ray diffraction (XRD) analysis}

Figure 7a and 7b shows the XRD spectra for microfibers and nanofillers, respectively. Both samples exhibited their main crystalline peaks at $16.8^{\circ}, 22.6^{\circ}$ and $34.9^{\circ}$, which corresponding to the (110), (200), and (004) planes crystallography. It was in response to the distinctive lignocellulosic material with I $\beta$ native cellulose structure. Meanwhile, the peak at $22.6^{\circ}$ was observed broadening for nanofillers and had somehow overlapping the peak at $16.8^{\circ}$ when comparing to microfibers sample. This indicated the crystals domain in nanofillers sample was decreased and the fiber bonding structure became homogeneous possibly resulted by the amorphization effect of ball milling [34,39]. From crystallinity measurement, the microfibers gave a crystallinity index of $71.8 \%$, which slightly higher than the crystallinity of nanofillers with $68.9 \%$. Nonetheless, the obtained crystallinity in this work is considerably high for nanofillers fiber (68.9\%), evidencing its highly crystalline structure is still preserved although undergoing harsh mechanical grinding process. It would endow it with great rigidity for acting as loadbearing agent in material reinforcement application.

\section{Conclusions}

The major findings of present work revealed the nanofillers were successfully produced from date palm based microfibers by only using mechanical ball milling process without involving any chemical reagents and/or other combined treatments. From morphology examination, the resulting nanofillers presented smooth surface with a mix of quadrilateral and irregular shapes of nanoscale feature. Besides this, the crystallinity analysis revealed the rigidity of nanofillers had decreased as compared to microfibers, showing the ball milling treatment could aid in improving fibers amorphous domains. Also, the thermal analysis showed that the microfibers had better stability of heat resistance comparing to nanofillers fiber, 
which affected by the reduced crystallinity and nano-sized structure. Nonetheless, when in view of the overall results, it suggests that the prepared nanofillers in this work can be utilized for reinforcing polymer composites in the future.

\section{Declarations}

\section{Acknowledgement}

The Project was funded by the National Plan for Science, Technology, and Innovation (MAARIFAH), King Abdulaziz City for Science and Technology, Kingdom of Saudi Arabia, Award Number (2-17-02-001-0061).

\section{Conflicts of Interest}

The authors declare no conflict of interest.

\section{References}

1. Satyanarayana KG, Arizaga GG, Wypych F (2009) Biodegradable composites based on lignocellulosic fibers-an overview. Prog Polym Sci 34:982-1021.

2. Gurunathan T, Mohanty S, Nayak SK (2015) A review of the recent developments in biocomposites based on natural fibres and their application perspectives. Compos Part Appl Sci Manuf 77:1-25.

3. Yan L, Kasal B, Huang L (2016) A review of recent research on the use of cellulosic fibres, their fibre fabric reinforced cementitious, geo-polymer and polymer composites in civil engineering. Compos Part B Eng 92:94-132.

4. Yousef $S$, Tatariants $M$, Tichonovas $M$, Kliucininkas L, Lukošiūtė SI, Yan L (2020) Sustainable green technology for recovery of cotton fibers and polyester from textile waste. J Clean Prod 254:120078.

5. Fonseca CS, Silva MF, Mendes RF, Hein PRG, Zangiacomo AL, Savastano Jr H, Tonoli GHD (2019) Jute fibers and micro/nanofibrils as reinforcement in extruded fiber-cement composites. Constr Build Mater 211:517-527.

6. Wu J, Du X, Yin Z, Xu S, Xu S, Zhang Y (2019) Preparation and characterization of cellulose nanofibrils from coconut coir fibers and their reinforcements in biodegradable composite films. Carbohydr Polym 211:49-56.

7. Manaia JP, Manaia AT, Rodriges L (2019) Industrial hemp fibers: an overview. Fibers 7:106.

8. Kajeiou M, Alem A, Mezghich S, Ahfir ND, Mignot M, Devouge-Boyer C, Pantet A (2020) Competitive and non-competitive zinc, copper and lead biosorption from aqueous solutions onto flax fibers. Chemosphere 260:127505.

9. Pirmohammad S, Shokorlou YM, Amani B (2020) Laboratory investigations on fracture toughness of asphalt concretes reinforced with carbon and kenaf fibers. Eng Fract Mech 226:106875.

10. Rocky BP, Thompson AJ (2020) Production and modification of natural bamboo fibers from four bamboo species, and their prospects in textile manufacturing. Fibers Polym 21:2740-2752. 
11. Soares LDS, Maia AA, Moris VA, De Paiva JM (2020) Study of the effects of the addition of coffee grounds and sugarcane fibers on thermal and mechanical properties of briquettes. J Nat Fibers 17:1430-1438.

12. Ling S, Qin Z, Li C, Huang W, Kaplan DL, Buehler MJ (2017) Polymorphic regenerated silk fibers assembled through bioinspired spinning. Nat Commun 8:1-12.

13. Pirmohammad S, Shokorlou YM, Amani B (2020) Influence of natural fibers (kenaf and goat wool) on mixed mode I/II fracture strength of asphalt mixtures. Constr Build Mater 239:117850.

14. Bezazi A, Amroune S, Scarpa F, Dufresne A, Imad A (2020) Investigation of the date palm fiber for green composites reinforcement: quasi-static and fatigue characterization of the fiber. Ind Crops Prod 146:112135.

15. Muthukumar K, Sabariraj RV, Kumar SD, Sathish T (2020) Investigation of thermal conductivity and thermal resistance analysis on different combination of natural fiber composites of banana, pineapple and jute. Mater Today Proc 21:976-980.

16. Naveen J, Jawaid M, Amuthakkannan P, Chandrasekar M (2019) Mechanical and physical properties of sisal and hybrid sisal fiber-reinforced polymer composites. In: Jawaid M, Thariq M, Saba N (ed) Mechanical and physical testing of biocomposites, fibre-reinforced composites and hybrid composites; Elsevier 427-440.

17. Ribeiro B, Yamashiki Y, Yamamoto T (2020) A study on mechanical properties of mortar with sugarcane bagasse fiber and bagasse ash. J Mater Cycles Waste Manag 22:1844-1851.

18. Cai Y, Liang Y, Navik R, Zhu W, Zhang C, Pervez MN, Wang Q (2020) Improved reactive dye fixation on ramie fiber in liquid ammonia and optimization of fixation parameters using the taguchi approach. Dyes Pigments 183:108734.

19. Labidi K, Cao Z, Zrida M, Murphy A, Hamzaoui AH, Devine DM (2019) Alfa fiber/polypropylene composites: influence of fiber extraction method and chemical treatments. J Appl Polym Sci 136:47392.

20. Ghori W, Saba N, Jawaid M, Asim MA (2018) Review on date palm (Phoenix Dactylifera) fibers and its polymer composites. In: Proceedings of the IOP conference series: materials science and engineering; IOP Publishing 368:012009.

21. Ramesh M, Palanikumar K, Reddy KH (2017) Plant fibre based bio-composites: sustainable and renewable green materials. Renew Sustain Energy Rev 79:558-584.

22. Vinod A, Sanjay MR, Suchart S, Jyotishkumar P (2020) Renewable and sustainable biobased materials: an assessment on biofibers, biofilms, biopolymers and biocomposites. J Clean Prod 258:120978.

23. Prasanna GV (2021) Surface modification, characterization and optimization of hybrid bio composites. In: Seetharamu S, Jagadish T, Malagi RR (eds) Fatigue, Durability, and Fracture Mechanics; Springer 623-632.

24. Yildizhan S, Calik A, Ozcanli M, Serin H (2018) Bio-composite materials: a short review of recent trends, mechanical and chemical properties, and applications. Eur Mech Sci 2:83-91. 
25. Alotaibi MD, Alshammari BA, Saba N, Alothman OY, Sanjay MR, Almutairi Z, Jawaid M (2019) Characterization of natural fiber obtained from different parts of date palm tree (Phoenix Dactylifera L.). Int J Biol Macromol 135:69-76.

26. Yi XS, Du S, Zhang L (2018) Different types of composite materials. In Composite Materials Engineering, Springer Volume 2.

27. Zwawi M (2021) A review on natural fiber bio-composites: surface modifications and applications. Molecules 26(2):404.

28. Mehanny S, Abu-El Magd EE, Ibrahim M, Farag M, Gil-San-Millan R, Navarro J, El-Kashif E (2021) Extraction and characterization of nanocellulose from three types of palm residues. $J$ Mater Res Technol 10:526-537.

29. Hussin FNNM, Attan N, Wahab RA (2020) Extraction and characterization of nanocellulose from raw oil palm leaves (Elaeis Guineensis). Arab J Sci Eng 45:175-186.

30. Khiari R, Belgacem MN (2020) Date palm nanofibres and composites. In: Midani M, Saba N, Alothman OY (eds) Date Palm Fiber Composites: Processing, Properties and Applications; Composites Science and Technology; Springer 185-206.

31. Alothman OY, Kian LK, Saba N, Jawaid M, Khiari R (2021) Cellulose nanocrystal extracted from date palm fibre: morphological, structural and thermal properties. Ind Crops Prod 159:113075.

32. Chen H (2015) Lignocellulose Biorefinery Engineering, 1st ed.; Woodhead Publishing: Cambridge, UK 37-86.

33. Tarrés Q, Pellicer N, Balea A, Merayo N, Negro C, Blanco A, Mutjé P (2017) Lignocellulosic micro/nanofibers from wood sawdust applied to recycled fibers for the production of paper bags. Int J Biol Macromol 105:664-670.

34. Saba N, Paridah MT, Khalina A, Nor-Azowa I (2015) Preparation and characterization of fire retardant nano-filler from oil palm empty fruit bunch fibers. BioResources 10(3):4530-4543.

35. Alotabi MD, Alshammari BA, Saba N, Alothman OY, Kian LK, Khan A, Jawaid M (2020) Microcrystalline cellulose from fruit bunch stalk of date palm: isolation and characterization. $J$ Polym Environ 28:1766-1775.

36. Hachaichi A, Kouini B, Kian LK, Asim M, Jawaid M (2021) Extraction and characterization of microcrystalline cellulose from date palm fibers using successive chemical treatments. J Polym Environ.

37. Abeer MA, Amira ME, Atef I, Mona K (2019) Chitosan/nanocrystalline cellulose biocomposites based on date palm (Phoenix Dactylifera L.) sheath fibers. J Renew Mater 7(6).

38. Rosli NA, Ahmad I, Abdullah I (2013) Isolation and characterization of cellulose nanocrystals from Agave angustifolia fibre. BioResources 8(2).

39. Alshammari BA, Alotaibi MD, Alothman OY, Sanjay MR, Kian LK, Almutairi Z, Jawaid M (2019) A new study on characterization and properties of natural fibers obtained from olive tree (Olea europaea L.) residues. J Polym Environ 27:2334-2340. 


\section{Figures}
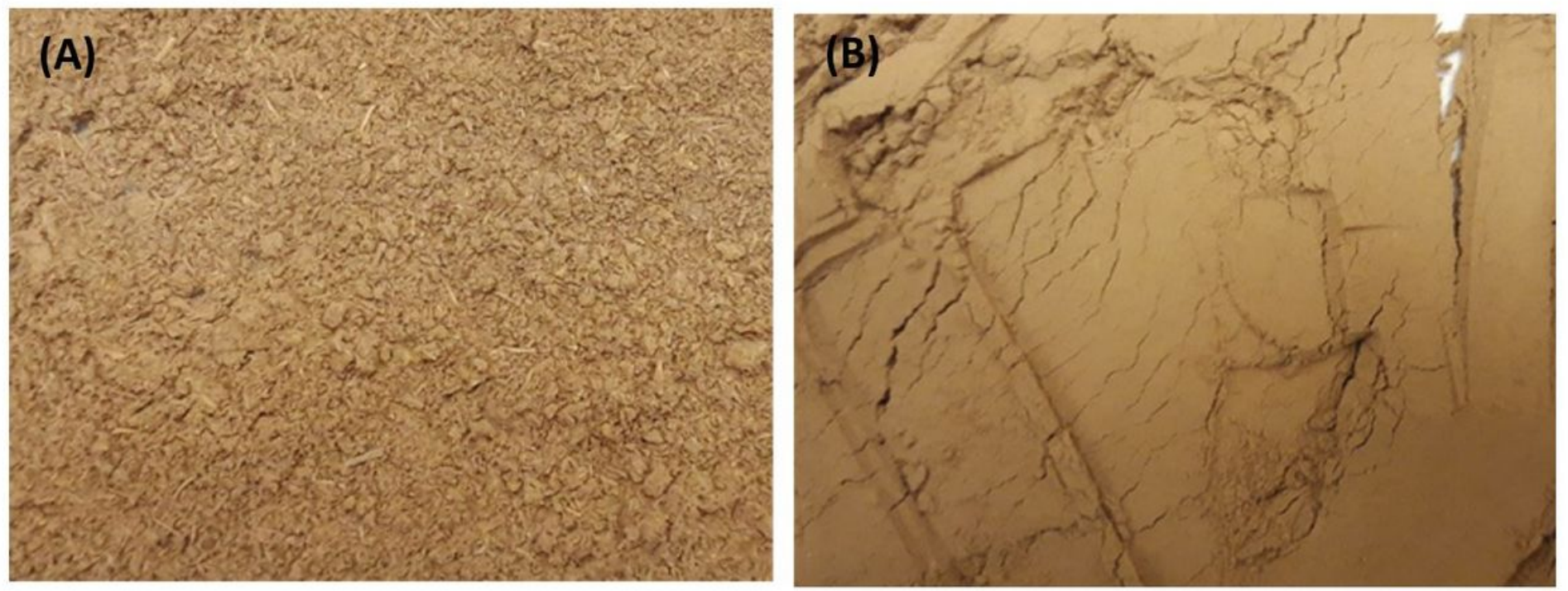

\section{Figure 1}

Digital images of (A) microfibers and (B) nanofillers
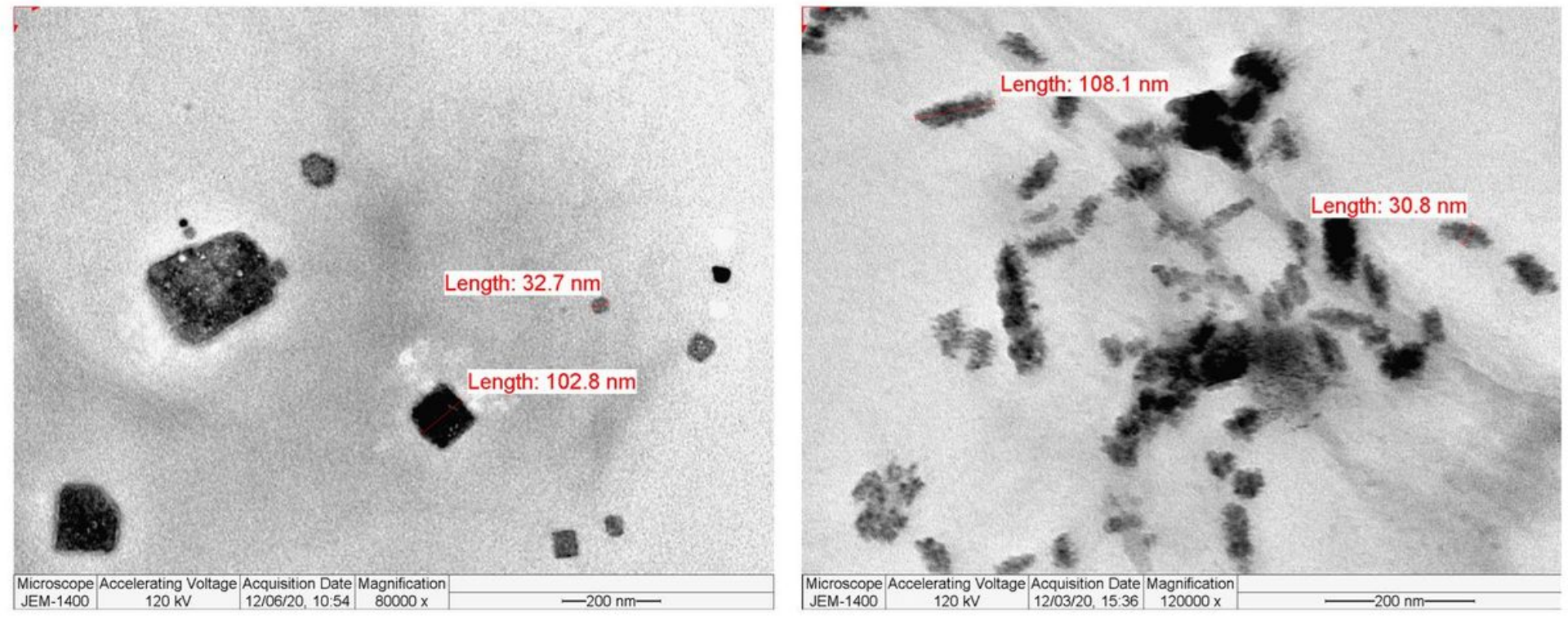

Figure 2

TEM images of nanofillers. 

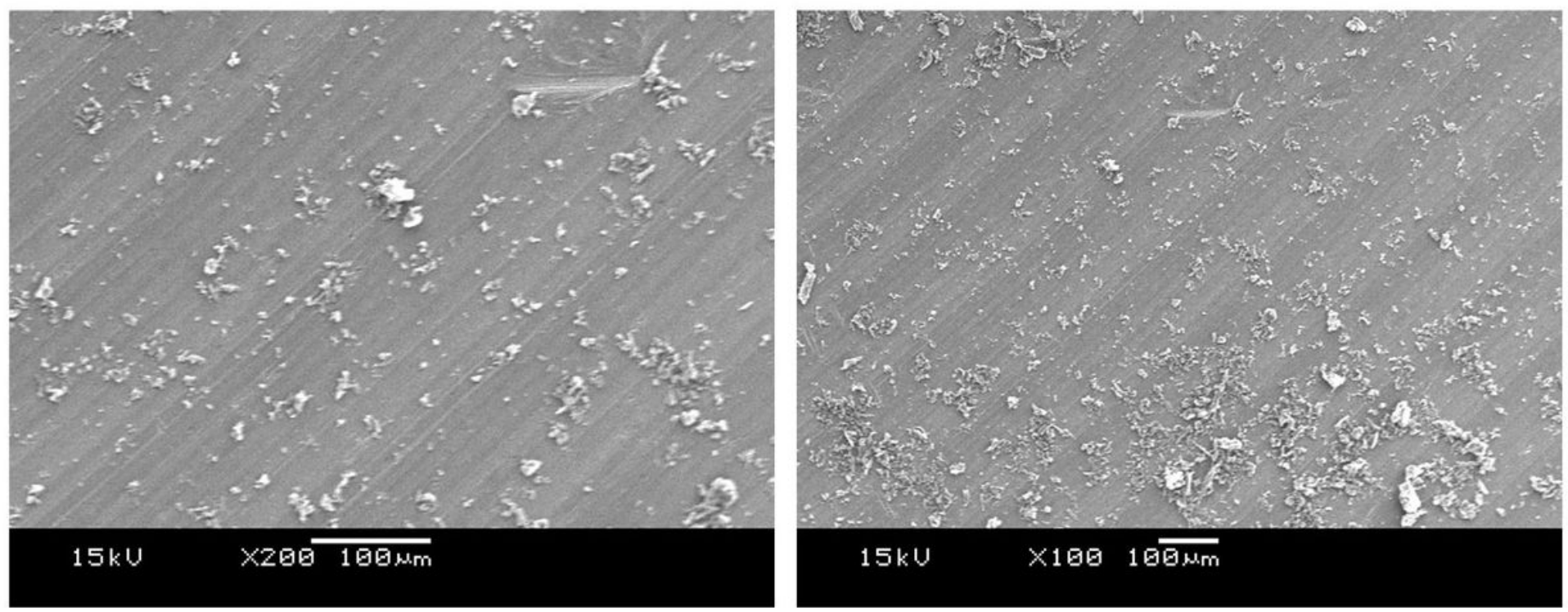

Figure 3

SEM images of microfibers. 

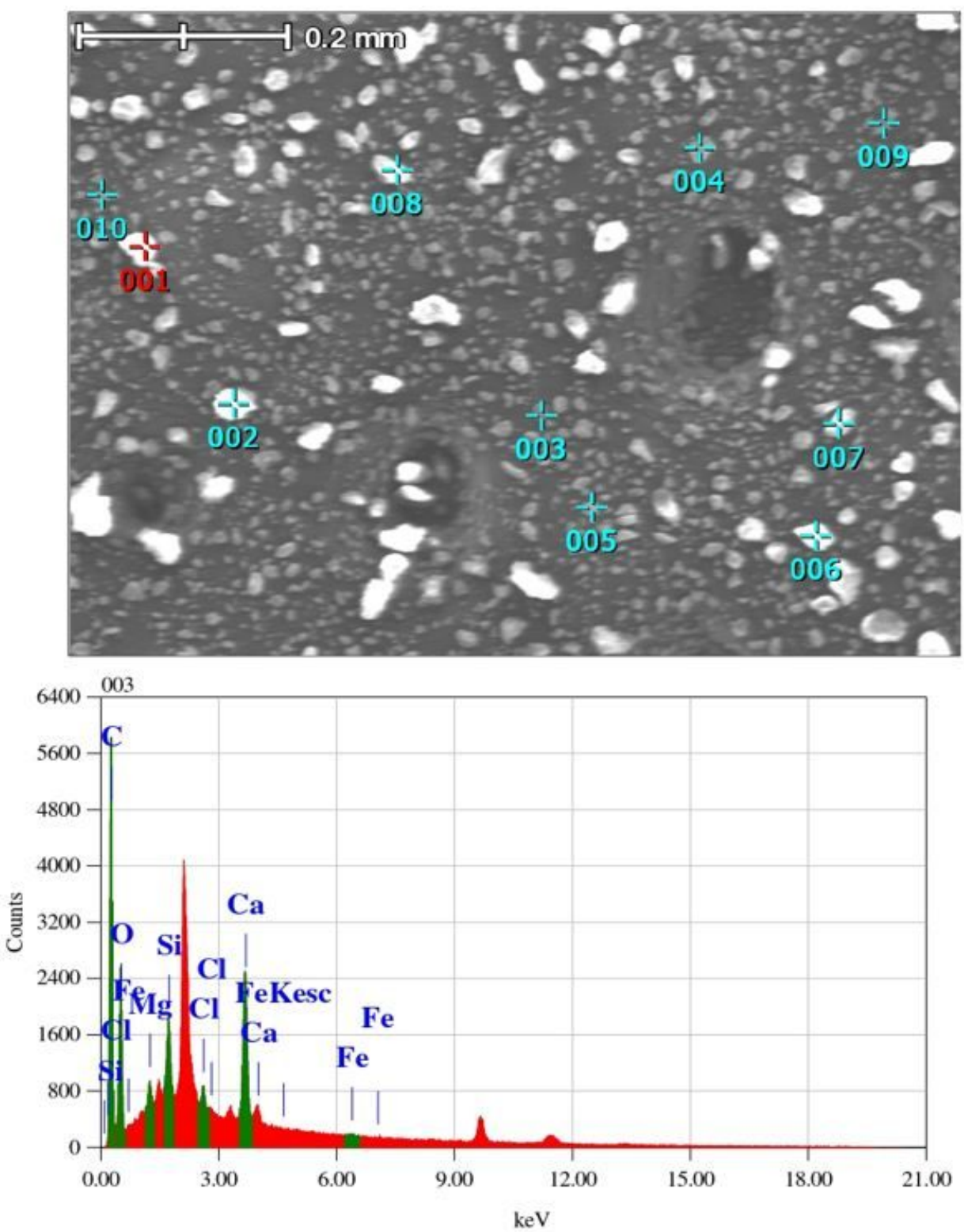

Acquisition Parameter

Instrument : 6360 (LA)

Acc. Voltage : $20.0 \mathrm{kV}$

Probe Current: $1.00000 \mathrm{nA}$

PHA mode : T3

Real Time : $132.83 \mathrm{sec}$

Live Time: $100.00 \mathrm{sec}$

Dead Time : 26 \&

Counting Rate: $5122 \mathrm{cps}$

Energy Range : $0-20 \mathrm{keV}$

ZAF Method Standardless Quantitative Analysis

Fitting Coefficient : 0.8666

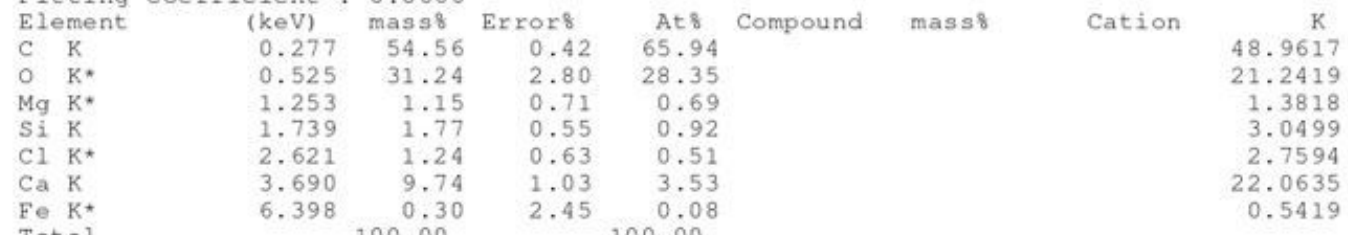

Figure 4

EDX spectrum of microfibers. 


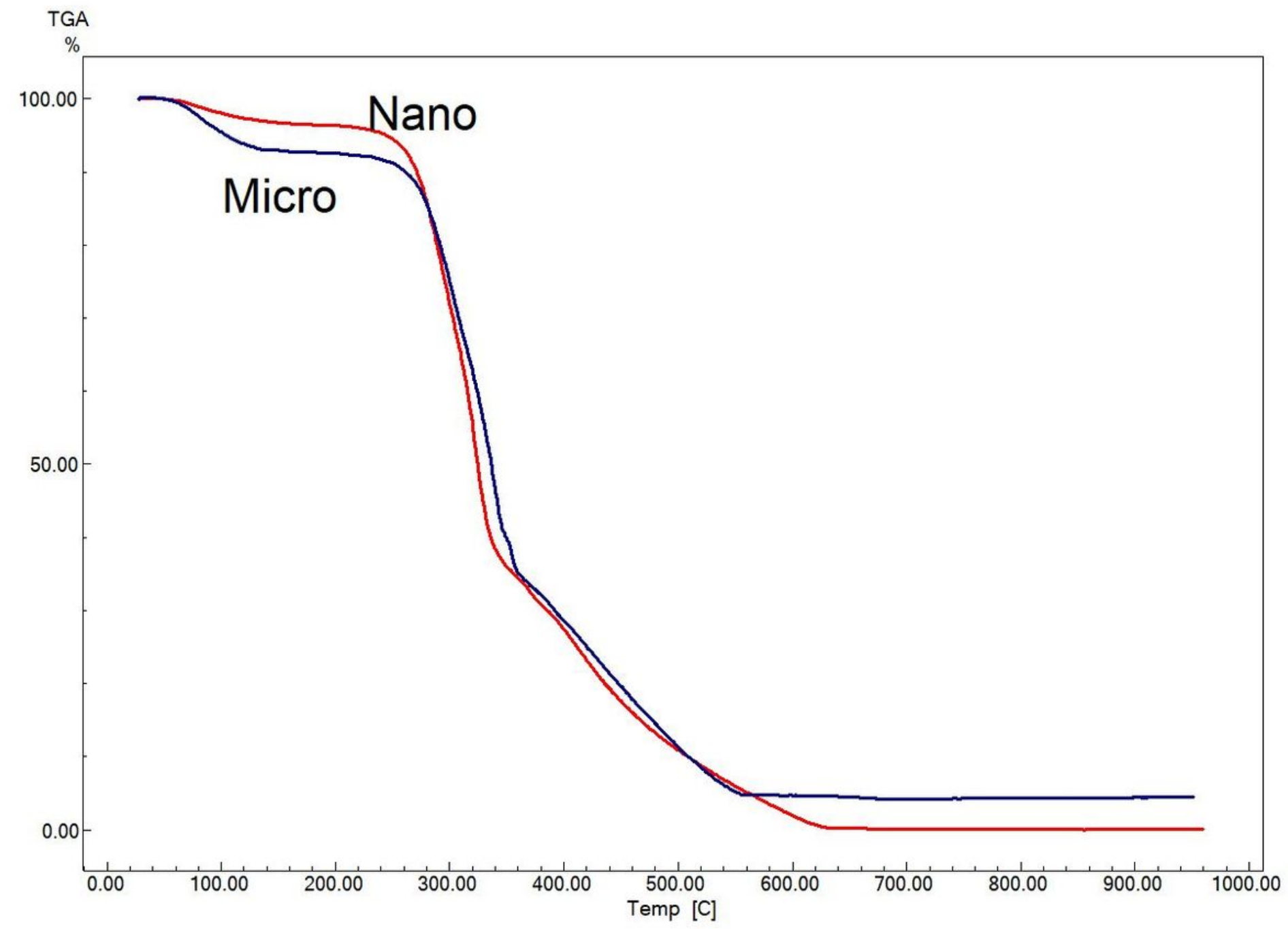

Figure 5

TGA curves of microfibers and nanofillers
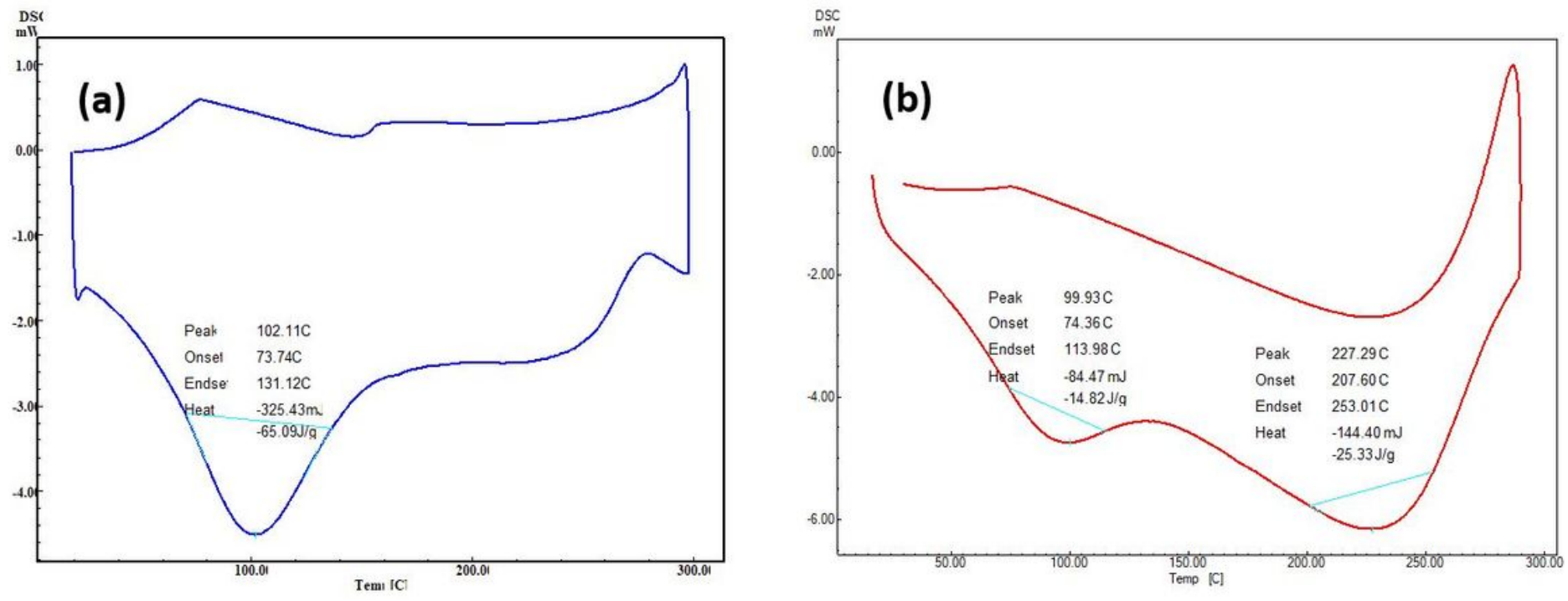

Figure 6 
DSC curves of (a) microfibers and (b) nanofillers.
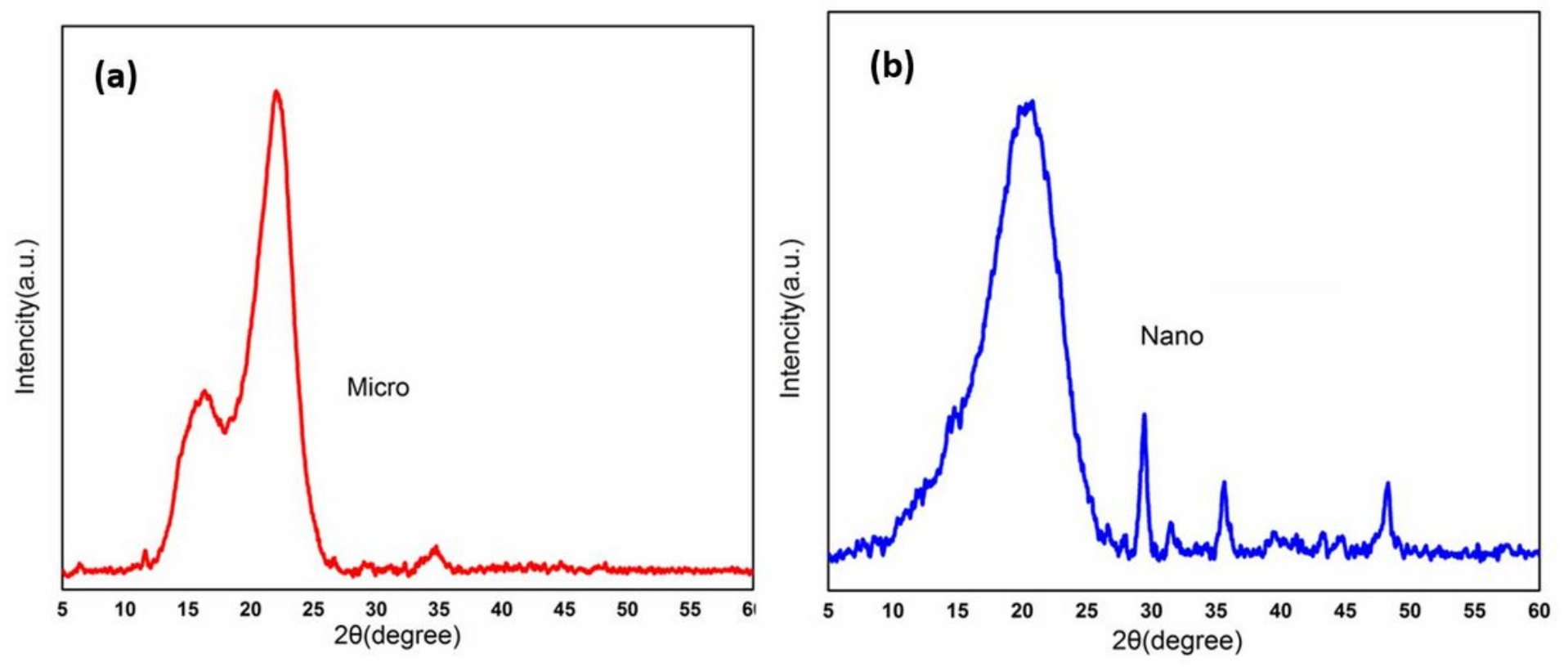

Figure 7

X-ray diffraction spectra of (a) microfibers and (b) nanofillers. 